\title{
CRENÇAS E MOTIVAÇÃO: MARCAS NO PROCESSO DE ENSINO E APRENDIZAGEM
}

\author{
Caroline Mitidieri Selvero é aluna regular de mestrado do Programa de Pós-Graduação em Letras da UFSM, área de Estudos \\ Linguísticos. \\ E-mail: caromiti@yahoo.com.br
}

Resumo

O presente trabalho apresenta alguns pressupostos teóricos acerca das crenças e da motivação que estão envolvidas no processo de ensino e aprendizagem de línguas estrangeiras instrumentais. Parte-se da conjectura de que o ensino instrumental de línguas procura capacitar o aluno em um curto espaço de tempo, buscando atender suas necessidades no sentido acadêmico e/ou profissional em um ambiente em que a interação é um aspecto preponderante. A partir daí, pretende-se salientar de que modo as crenças e a motivação podem influenciar no referido processo.

\begin{abstract}
Resumen
Este artículo presenta algunos presupuestos teóricos acerca de las creencias y motivaciones que están implicados en la enseñanza y en el aprendizaje de lenguas extranjeras instrumentales. Se piensa que la enseñanza de lengua instrumental trata de capacitar a los estudiantes en un corto período de tiempo, tratando de satisfacer sus necesidades en el sentido académico y/o profesional en un ambiente donde la interacción es un aspecto muy importante. Después de eso, tenemos la intención de poner de relieve cómo las creencias $\mathrm{y}$ motivaciones pueden influir en ese proceso.
\end{abstract}

\section{1) CONSIDERAÇÕES INICIAIS}

Grande parte das teorias da aquisição de língua estrangeira, em termos da formação integral do indivíduo, oferece aos fatores emocionais e aos cognitivos uma importância considerável. Desse modo, é possível considerar que, em qualquer tipo de manifestação, as emoções são fundamentais para auxiliar as pessoas na realização de suas tarefas e no alcance de seus objetivos com eficiência. A interação, nesse sentido, é essencial para favorecer a aprendizagem e apoiar as relações interpessoais da linguagem.

Nesse contexto, compreende-se que existem saberes e linguagens entre os sujeitos que socializam experiências, idéias e conhecimentos, que marcam as diferenças existentes entre os indivíduos. Nessa conjuntura, a sala de aula é um ambiente que exige do professor um preparo para mediar as relações subjetivas que afloram do convívio aluno-aluno, aluno-professor e do contado com os novos conhecimentos que são oferecidos no ambiente de estudo.

A educação cumpre, nas sociedades humanas, uma função muito importante. Segundo Charlot (2000), ao ingressar no mundo, o indivíduo tem a obrigação de aprender. Desde seu nascimento, o ser humano estabelece relações com o meio que o cerca, vivencia experiências, adquire saberes e vai atribuindo sentido para seu ambiente. Aprender significa mais que memorizar saberes. É um processo contínuo de autoconstrução, de um ser humano capaz de atuar na realidade. 
Neste sentido, Maturana (2004) considera que é a partir das redes de conversação ${ }^{i}$ materno-familiar que o indivíduo começa a significar o mundo. As canções de ninar de sua mãe, as lições de certo e errado dadas por seus pais e o convívio com os irmãos são as primeiras experiências que lhe dão base para entender a si mesmo e a realidade em que se encontra. A educação pode ser vista, então, como um processo contínuo em que o ser humano vai inserir-se, construir sentido e atuar no mundo em que vive.

Nessa sua trajetória, o indivíduo vai ampliando suas redes de conversação, mais especificamente, da família, dos amigos, dos vizinhos chegando à escola. Essa instituição de ensino, como o primeiro local em que a criança tem o convívio social, apresentará a vida em grupo, que é de grande importância para o seu crescimento e amadurecimento.

Segundo Chalita (2001), o contexto escolar deve preparar os estudantes para entender e intervir no mundo em que vivem. Desse modo, a educação deverá de ser ampla, para auxiliar na formação e preparação de seres completos, únicos e críticos. Assim, a escola pode ser considerada um lugar de educação e de conhecimento indispensáveis para o desenvolvimento humano.

$\mathrm{O}$ ato educativo deve estar a serviço do desenvolvimento e do bem-estar do homem em harmonia com ele mesmo e com o meio em que vive. A educação, assim, é uma iniciação à vida, não sendo somente transmissão de um saber, do conhecimento ou de uma conduta. Para Freire (2004), formar vai além de simplesmente treinar o aluno, envolvendo o processo de construção e reconstrução de sujeitos participantes do processo de educar.

O papel do professor pode apresentar uma importância significativa na construção da auto-imagem do aluno. O seu método de ensinar, as suas atitudes, o carinho e o interesse que demonstra em aula influencia no desenvolvimento da motivação e na sua aprendizagem. Seguindo o raciocínio de Collins (2004), os adultos demonstram estar mais motivados no processo de ensino e aprendizagem quando este é mais dirigido, específico para a necessidade que os aprendizes possuem. $\mathrm{O}$ aluno mais maduro cronologicamente traz consigo um depósito de experiência e de aprendizagem prévia para qualquer novo processo de aprendizagem.

Dentro desse pressuposto, quando a aprendizagem está relacionada ao trabalho do educando, os alunos valorizam as informações que recebem por serem mais curiosos intelectualmente, mais motivados para aprender e responsáveis por se tratarem de pessoas adultas, com objetivos definidos. Assim, o professor é apreciado enquanto um facilitador da aprendizagem de forma que os aprendizes se mostram extremamente envolvidos na obtenção de conhecimento. O professor, com isso, deve apresentar um interesse em reconhecer que seus alunos possuem estilos diferentes de aprender e que, estes devem ser respeitados.

Os adultos desejam um curso de língua que seja relevante e prático. Dentro dessa conjuntura, o ideal é a união da aprendizagem ao trabalho, por meio de ensinamentos que sejam aplicados a situações da vida real. Observa-se que os alunos se 
envolvem mais nos casos de problemas centralizados, aplicações práticas relacionados às suas necessidades. Assim sendo, a participação ativa de adultos é fortalecida através de atividades centradas no estudante, com o estímulo de suas razões para participar e com a diminuição de suas barreiras para a aprendizagem.

Com isso, encontrou-se no ensino instrumental uma opção para as pessoas com interesse profissional e/ou acadêmico satisfazerem-se com uma aprendizagem de língua estrangeira em um pequeno espaço de tempo e para um fim específico. A partir desses pressupostos, pretende-se investigar em que sentido as crenças e a motivação podem ser um fator diferencial no processo de ensino e ELE.

\section{2) CRENÇAS SOBRE A APRENDIZAGEM DE LÍNGUAS}

O estudo sobre crenças na aprendizagem de línguas é um assunto relativamente novo em Lingüística Aplicada (LA) e "é um dos campos de investigação que tem se tornado fértil" (Silva, 2010, p. 21), pois conforme aponta Barcelos (2004) as pesquisas a respeito desse tema começaram por volta da década de 80 no exterior, e no Brasil, por volta dos anos 90 .

As crenças para Viana (2010) têm um papel essencial para todo o ser humano porque influenciam em demasia na maneira de ensinar e de aprender LE ${ }^{\mathrm{ii}}$. Evidencia-se que o interesse por estudar e investigar as crenças de professores e alunos sobre ensino e aprendizagem de língua tem crescido desde o seu surgimento. Esse fato justifica-se em função de servir como um auxílio para o entendimento da forma como as pessoas pensam e da maneira como o ser humano age em determinadas situações.

As crenças para Barcelos (2004), são conceitos cognitivos, sociais, interativos, recíprocos e dinâmicos, que estão relacionados com as experiências e com a forma como se pensa e se reflete sobre elas. A partir dessas colocações, é possível dizer que as crenças são construídas e modificadas na experiência, na interação com os indivíduos com que o sujeito convive.

De acordo com Barcelos (2001), o estudo de crenças vai além do que simplesmente uma descrição, porque procura também contextualizá-las e investigá-las. Assim, é importante compreendê-las como presentes no processo interativo que ocorre com os alunos e exercem uma determinada função nas experiências que são construídas dentro da sala de aula. O contexto, nesse sentido é fundamental, pois não apenas influencia, mas é influenciado nesse processo.

Para Silva (2011), a maior parte das definições realizadas sobre crenças consideram o contexto social em que professores e alunos estão inseridos, de forma que as crenças não são estanques, modificando-se de indivíduo para indivíduo. Cada pessoa faz parte de um contexto social e tem a sua própria experiência de vida e é influenciada por ela.

Pode-se definir que crenças sobre o ensino de línguas é o que o sujeito acredita (consciente ou inconscientemente) em relação ao processo de ensino-aprendizagem e de avaliação de línguas. Desse modo, tudo que for resultante da experiência e do estudo do 
indivíduo, considerando a influência da idade e o contexto de interação, pode ser considerado como crenças. As crenças são; portando, socialmente (cultural e historicamente) construídas pela interação e mantêm uma acentuada relação com a ação. Alvarez (2007) propõe uma autêntica visão de crença:

A crença constitui uma firme convicção, opinião e/ou ideia que tem o indivíduo com relação a algo. Essa convicção está ligada a intuições que tem como base as experiências vivenciadas, o tipo de personalidade e a influência de terceiros, pois elas são construídas socialmente e repercutem nas suas intenções, ações, comportamento, atitude, motivações e expectativas para atingir um determinado objetivo. Elas podem ser modificadas com o tempo, atendendo às necessidades do indivíduo e a redefinição de seus conceitos, se convencido de que tal modificação lhe trará benefícios (Alvarez, 2007, p.200).

A crença, segundo Ortiz (2007, p. 200), "constitui uma firme convicção, opinião e/ou ideia que tem o indivíduo em relação a algo". Essa certeza tem como base intuições relacionadas com as experiências de vida, com o tipo de personalidade e com a influência de outras pessoas com as quais o indivíduo convive. Pode-se deduzir que as crenças são construídas socialmente e repercutem nas ações, nas motivações e nas expectativas que o sujeito apresenta para atingir um determinado objetivo. Além disso, podem ser modificadas no decorrer do tempo, pois atendem às necessidades do sujeito.

\section{1) Crenças de Professores}

Em consonância com Silva (2011), quando se procura pensar sobre as crenças dos professores de LE busca-se que é possibilitar refletir acerca de suas ações para que se possa transformar o ensino no contexto onde atuam. Considera-se que as crenças educacionais dos professores podem influenciar nos procedimentos em sala de aula sendo, por isso, acentuada a importância de explicitar as suas concepções para que consigam ser alteradas, caso seja necessário.

As crenças e os valores podem servir de suporte para uma série de decisões e ações tomadas pelos docentes; nesse emaranhado é formulada a então conhecida como cultura de ensino. Cada docente também possui crenças sobre os programas de ensino com que trabalham e pode exercer influências em outros colegas de trabalho, principalmente nos menos experientes. É indiscutível que as crenças que os docentes carregam consigo afetam tudo o que eles fazem em sala de aula.

Nessa perspectiva, os sistemas de crenças dos professores podem ser compreendidos como fundidos em objetivos, valores e crenças que esses profissionais possuem em relação ao conteúdo, ao processo de ensino, à compreensão dos sistemas em que trabalham e aos papéis que são desempenhados nesses sistemas, conforme Richards (2002). Por isso, pode-se compreender que o processo de ensino é uma atividade extremamente pessoal, o que favorece que cada professor possua suas crenças relacionadas com a maneira como acredita que ocorra uma aprendizagem eficaz. 
Para Ortiz (2007), as expectativas negativas que o professor possui de seus alunos, as crenças individuais que cada docente traz consigo não só os seus objetivos e os seus valores em relação ao seu papel de ensino e aprendizagem de LE podem ter uma conotação negativa. Do mesmo modo, uma atuação inibidora no desempenho e na motivação dos alunos resulta, na maioria dos casos, no fracasso ou na desistência dos discentes.

Williams (1999) destaca que os professores, além de influenciar na aprendizagem dos alunos, podem motivá-los, aumentar o interesse pessoal, a confiança, a autoestima e, por fim, organizar o entorno ideal para a aprendizagem, o que salienta a importância do contexto, do entorno escolar no qual o aluno está inserido. Segundo Burocovitch (2009, p. 125) "todo professor deve proporcionar aos alunos reais experiências de êxito, comunicar-lhes expectativas quanto às suas capacidades e evitar ocorrências e verbalizações que possam gerar dúvidas sobre elas". Com isso, entende-se a importância das crenças e das expectativas que o docente possui do processo de ensino/aprendizagem, porque isso influenciará na motivação para que o discente atinja seus objetivos.

A partir do ensino de línguas estrangeiras surgiu uma série de princípios que determinam a estrutura interna das aulas. Esses princípios são baseados no desenvolvimento de habilidades e de processos que sustentam os diversos aspectos do ensino de línguas estrangeiras e da eficácia da aprendizagem. O professor tem, com isso, uma tarefa muito importante:

Cabe ao professor, dentro de suas possibilidades, o máximo esforço possível para manter a motivação dos alunos que já a têm e despertá-la nos que se encontram desmotivados. É preciso ponderar, entretanto, que não há e não vai haver nenhuma receita mágica que possa ser usada por todos os professores, com todos os alunos, em quaisquer situações (Fernández, p. 48, 2010).

Para muitos professores, o enfoque de ensino é uma escolha extremamente pessoal, pois, os docentes desenvolvem papéis para serem desempenhados em aula baseados em suas teorias de ensino, aprendizagem e de interação que devem adequar-se às teorias escolhidas.

\section{2) Crenças de Alunos}

Em estudos sobre crenças realizado em Hong Kong, Richards (2002) comprovou que os melhores alunos em aula, com mais aproveitamento eram os que estavam motivados, ativos e participativos. Da mesma forma, eram os que não possuíam medo de cometer erros e ainda conseguiam trabalhar de maneira autônoma, sem o auxílio do professor. É possível pensar, assim, que os discentes também trazem suas crenças pessoais, objetivos, atitudes e decisões para o processo de aprendizagem.

Essas crenças abrangem uma gama ampla de assuntos que influenciam na motivação para aprender, nas expectativas relacionadas com a aprendizagem de línguas 
e em seus sentimentos ou percepções sobre o que é mais fácil e difícil de aprender em uma língua.

Dentro dessa perspectiva, os alunos podem ter opiniões acerca da interação em sala de aula e do comportamento adequado em aula. No entanto, discentes de diferentes culturas apresentam distintas crenças e opiniões específicas sobre o que é um bom ensino. Isso pode ter raiz cultural ou estar em contradição com as crenças dos professores. Destarte, as crenças dos estudantes estão influenciadas pelo contexto social da aprendizagem de línguas estrangeiras.

As crenças dos alunos também podem depender do estilo de aprendizagem que eles seguem, ou seja, discentes com um enfoque comunicativo de aprendizagem preferem um estilo social de aprendizagem. Necessitam, com isso, da participação de outras pessoas, de interações e aprendem com mais facilidade a partir do uso de atividades em grupo.

\section{3) Crenças de Alunos e Professores}

A interação, de maneira geral, tem uma influência na aprendizagem do aluno, pois se dedica muito tempo na relação entre aluno-aluno e aluno-professor, o que sugere que exista qualidade nesse procedimento. $\mathrm{O}$ interacionismo social destaca tanto a importância do contexto quanto a do o fundamento das interações sociais e comunicativas.

Os professores e os alunos, segundo Williams (1999), estão em uma contínua interação. Os valores e as crenças dos professores refletem no comportamento que eles mantêm em aula. No entanto, as reações dos alunos diante dos docentes estão influenciadas pelas suas características individuais e pelos sentimentos que os professores transmitem.

Aprender um idioma estrangeiro é um processo que vai além de decorar regras gramaticais, pois envolve um interagir com o outro e em diversas situações desconstruir velhas significações. Não existe dúvida de que a aprendizagem de idiomas tem um caráter social, de tal maneira que a linguagem faz parte da essência social do sujeito, além de constituir sua identidade e ser utilizada para transmitir informações para outras pessoas, seguindo Williams (1999). A interação é fundamental para o ensino de língua estrangeira:

Nesse sentido, ensinar uma língua estrangeira não deve consistir apenas em transmitir conhecimentos linguísticos ao aluno, mas principalmente deve provocar nele o interesse pelo outro, por novas culturas, outros modos de enxergar a realidade, ampliando suas possibilidades de comunicação e de interação social (Fernández, 2010, p.12).

O professor, segundo Hernández (2010), pode aplicar em aula um questionário com o qual consiga ter conhecimento do nível de motivação de cada aluno. As diferenças entre as crenças de professores e alunos, segundo Richards (2002), podem 
produzir interferências nas suposições sobre o trabalho em aula, assim como proporcionar uma desvalorização das atividades aplicadas pelos professores.

A partir do desenvolvimento das atividades em aula, é imprescindível que seja propiciada, tanto aos alunos quanto para o professor, a interação em um ambiente agradável. O ambiente em sala de aula é um fator fundamental para estimular a motivação dos alunos.

\section{3) ENSINO INSTRUMENTAL DE LÍNGUA ESTRANGEIRA}

O Ensino Instrumental de Língua Estrangeira, primeiramente trabalhando com a Língua Inglesa, de acordo com Freitas (2005), surgiu na década de 60. A partir dos anos 70, as publicações teóricas acentuaram-se e promoveram o desenvolvimento dessa modalidade. Segundo Sedycias (2002), o ensino instrumental ganhou mais prestígio durante a Segunda Guerra Mundial quando foi praticado nos EUA com os métodos áudio-oral e áudio-visual. Seu objetivo era de ensinar línguas européias aos soldados americanos.

No Brasil, de acordo com Martins (2009), o ensino instrumental de línguas teve seu início nos anos 70 com a adoção do projeto Ensino de Inglês Instrumental em Universidades Brasileiras. A partir daí, ficou acentuada a necessidade de um ensino voltado para a habilidade de leitura de textos científicos, auxiliando os alunos acadêmicos na realização de leituras, de interpretação e de compreensão de textos.

Para Nardi (2005), o ensino de línguas está em constante modificação, o que causa a busca de diversas alternativas, métodos e abordagens que satisfaçam as necessidades do aluno. Foi dessa forma que surgiu o inglês instrumental, ou seja, procurando sanar a crescente necessidade pela aprendizagem de língua estrangeira e, além disso, possibilitar a aprendizagem de um idioma em um curto período de tempo.

De acordo com Ramos (2005), com o passar dos anos e em função da necessidade de adquirir novas competências, o ensino instrumental passou a atender também a competência comunicativa, com vistas a desenvolver a oralidade. A abordagem de ensino instrumental, segundo Sedycias (2002), está relacionada a objetivos específicos, à capacitação do aluno em língua estrangeira, em pouco tempo e para a atuação em determinada tarefa. Desse modo, o aluno conseguiria desempenhar-se melhor em uma função linguística determinada.

A partir dessa prática educativa, o aluno é auxiliado a superar dificuldades dentro de um contexto determinado, o que o ajuda no desenvolvimento de destrezas específicas em uma determinada língua. Esse fato tem apresentado enormes contribuições para os estudantes de ensino instrumental de LE, de maneira que se encontram mais motivados a buscar esse tipo de prática por fornecer assistência no sentido profissional, por exemplo.

O ensino instrumental de línguas, segundo Ramos (2005), é uma abordagem de ensino voltada para a aprendizagem de língua estrangeira e propõe-se, fundamentalmente, ao atendimento das necessidades do aluno, no sentido do ensino 
estar voltado para o que o aluno vai precisar saber para poder atuar na situação-alvo. Dessa forma, ele vai aprender a língua para desempenhar tarefas específicas em situações pré-determinadas.

Seguindo a mesma reflexão, Claxton (2005) explicita que a capacidade para a aprendizagem pode ser desenvolvida e as dificuldades superadas quando o aprendiz está nas condições adequadas. Assim, o aprender é um procedimento intrínseco que está ao alcance de todos que percebem as possibilidades e os recursos que o processo pode oferecer.

Com isso, nessa abordagem, a língua é vista como um meio, um instrumento para alcançar algo, pois os objetivos já devem estar definidos. Desse modo, o material didático deve ser autêntico, composto por atividades que aproximem o estudante da realidade desenvolvida especificamente para alcançar o seu interesse. Já o grupo de alunos deve ser homogêneo, composto por pessoas adultas que possuem a mesma finalidade.

Além disso, ressalta-se que os temas a serem estudados em um curso instrumental de línguas devem estar diretamente relacionados com a área de atuação do aluno, ou seja, referentes ao seu campo profissional ou de estudo:

\footnotetext{
Quanto ao mundo do trabalho, os reflexos já se fazem sentir mais de perto em cursos de graduação, como hotelaria, turismo, relações internacionais, entre outros, nos quais os alunos muitas vezes já estão atuando no mercado e pedem ao professor o aprendizado de tarefas a serem desempenhadas no trabalho. No que tange a curso de inglês para negócios, a demanda deu um salto quantitativo muito grande. Ao mesmo tempo, cresce a demanda relativa a necessidades ocupacionais (taxistas, pilotos, recepcionistas, etc.) (Ramos, 2005, p. 119).
}

Para conseguir alcançar todas essas expectativas, García (2000) ressalta que o professor deve buscar atividades que unam a língua e a cultura de forma integral. Para isso, é fundamental que as atividades sejam elaboradas com bastante cuidado, com instruções claras e concisas, para que os alunos compreendam a finalidade de cada uma.

De acordo com Nardi (2005), no ensino instrumental, o aluno está em constante interação com o professor. Para isso, é fundamental que o professor esteja seguro o suficiente para compreender o que o aluno sabe e, assim, poder seguir os objetivos propostos pelo curso de línguas. Dessa forma, o conhecimento técnico do estudante pode ser mais importante que o do docente para determinar como as aulas serão seguidas.

O ensino de língua estrangeira para fins específicos tem mostrado excepcionais resultados. A possibilidade do aluno poder tornar-se auto-suficiente para o desempenho em LE faz com que ocorra um aumento da motivação do estudante para o aprendizado, bem como serve de um incentivo para que ele vá em busca do seu desenvolvimento e aperfeiçoamento em língua estrangeira.

\section{4) A MOTIVAÇÃO NO PROCESSO DE ENSINO E APRENDIZAGEM}


Antigamente o aluno era considerado um agente passivo, segundo Alvarez (2007), porque recebia os conhecimentos prontos e somente tinha a função de repeti-los. Nos dias atuais, a abordagem comunicativa proporciona o estabelecimento de um caminho inverso, no qual a participação do aluno recebe um significado e uma importância expressiva, de forma que o ensino torna-se centrado no aprendiz. Dessa maneira, ele "passa a ser visto como ser social afetivo com atitudes e motivações que o levam ao sucesso ou fracasso dependendo dos vários fatores ligados às questões psicológicas" (Alvarez, p. 191, 2007).

O conteúdo, o material didático, os métodos de ensino e as atividades de aprendizagem são componentes motivacionais específicos de cada curso ou disciplina. Como componentes motivacionais relacionados ao professor podem ser considerados o tipo de autoridade, as atividades, o feedback, a empatia, a sua formação linguística e a fluência, assim como a sua motivação pessoal. Segundo Fernández (2010), os componentes motivacionais referentes ao grupo são os seus objetivos, a competitividade, a cooperação e a individualidade.

Seguindo o pensamento de Williams (1999), a motivação somente tem sentido com uma ação concreta e, além disso, está composta por distintos fatores que podem ser classificados como interesse, curiosidade e o desejo por alcançar algo. Nessa perspectiva, a motivação pode ser considerada como algo que não é diretamente observável, pois é um construto, um processo que denota a participação de diversos fatores que estimulam a pessoa a agir de determinada maneira, seguindo os preceitos de Bzuneck (2004).

A motivação, em consonância com Knüppe (2006), deve estar presente em todos os momentos, pois é a base do estudo. Dessa forma, pode ser caracterizada como intrínseca e extrínseca. A motivação intrínseca é orientada nas expectativas e projeções do aluno, estando relacionada ao interesse pela própria atividade. É a motivação que resulta da natureza, está "relacionada com a própria tarefa a ser executada. O aluno se interessa pelo conteúdo e, à medida que passa a dominar conceitos e técnicas que lhe permitem aprofundar a matéria objeto de estudo, reforça sua motivação" (Fernández, p. 30, 2010). Enquanto isso, a extrínseca é marcada pelos estímulos externos, oriundos de terceiros direta ou indiretamente e está relacionada às rotinas das vidas dos sujeitos é, portanto, resultante da influência do meio.

Fernández (2010) admite que alunos motivados intrinsecamente se interessam pela aprendizagem, por isso são envolvidos no processo. Eles questionam, valorizam o que aprendem e participam ativamente dos exercícios propostos em aula. Os motivados extrinsecamente necessitam de incentivos externos para manterem-se envolvidos, pois se os incentivos diminuírem, a motivação também é atenuada.

Parece claro, segundo Fernández (2010), que a motivação está diretamente vinculada a aspectos psicológicos (autoestima, autoconfiança, autorealização) e, além disso, depende de outros fatores para manter-se. Por isso, fica evidente a necessidade do professor estimular o aluno para que ela perdure. É complexa e dinâmica, variando no

$$
\begin{gathered}
\text { Revista Escrita } \\
\text { Rua Marquês de São Vicente, 225 Gávea/RJ CEP 22453-900 Brasil } \\
\text { Ano 2012. Número 15. ISSN 1679-6888. } \\
\text { escrita@ puc-rio.br }
\end{gathered}
$$


tempo e de indivíduo para indivíduo. Ela surge como um elemento que parece ser responsável por "mover" o aluno para sair de seu estado de repouso e de conforto e ir em busca de uma ação transformadora.

Williams (1999) define alguns fatores que, caso estejam estimulados, motivam o aluno: o sentimento de competência ou a possibilidade de enfrentar qualquer tarefa; o controle do próprio comportamento como uma habilidade de controlar a própria aprendizagem; o planejamento de metas; o desafio para buscar coisas novas na vida; a consciência de troca de conhecimentos; a crença em resultados positivos; a cooperação entre os alunos; a individualidade ou a singularidade dos estudantes e o sentimento de afiliação que surge quando instigados favorecem ao aluno um sentimento de capacidade.

No momento do trabalho, quando o professor percebe que os alunos estão motivados, é gerado um sentimento de conforto e de satisfação que proporciona uma facilidade na interação aluno-professor e aluno-aluno, ou seja, os resultados que serão obtidos parecem ser melhores e o discente tem a sua motivação aumentada, em consonância com Fernández (2010).

A aprendizagem significativa, ocorre quando são despertados a coerência, a motivação e o interesse do aluno. Pode-se dizer que os fatores emocionais recebem uma significativa relevância:

A verdade é que nossos sentimentos, nossas paixões e anseios mais profundos constituem uma força extraordinária que, muito mais do que cultura, conduz nossas esperanças de felicidade. A evolução de nossa espécie deu à emotividade um papel essencial para a solução dos problemas mais proeminentes da vida. É ela que nos conduz quando surgem provocações essenciais para serem deixadas apenas à nossa pobre intelectualidade (Antunes, 2003, p. 23).

Os aspectos emocionais recebem uma significativa relevância, pois, segundo Chalita (2004), a habilidade emocional é fundamental para que o aprendiz consiga desenvolver suas habilidades cognitivas e sociais. Dentro dessa conjuntura, ao lidar com emoção, trabalha-se com a libertação do ser humano que começa a sentir-se autônomo e capaz de aprender coisas novas e produtivas. Desse modo, no processo de ensino e aprendizagem, tanto o educando como o educador estão em uma constante troca de informações, no qual pode ser criado um ambiente fértil e saudável para o debate e a reflexão:

O cognitivo não se dá de uma forma satisfatória sem esse pano de fundo da afetividade. Para que o estudante aprenda, ou para que nós educadores aprendamos, importa que a nossa afetividade e a do nosso educando nos disponibilize para aprender: "eu desejo aprender", "gosto de aprender", "estou disponível para aprender isso"; "tenho interesse nisso", "tenho prazer em aprender isso", "meus olhos brilham quando compreendo uma coisa nova"... Sem essa abertura afetiva, dificilmente alguém aprenderá efetivamente alguma. Mais que isso, sem ela, não se fará nada com satisfatoriedade, nem no trabalho, nem na vida pessoal, nem nos relacionamentos, nem nas experiências do sagrado... em lugar nenhum (Vasconcelos, 2009, P.2). 
Percebe-se o quanto é necessária uma reflexão acerca de uma verdadeira aprendizagem, que o estudante consiga refazer o que é ensinado e que seja um agente ativo do processo de ensino e aprendizagem. Ao pensar em uma prática educativa sem a aplicação da motivação e do interesse aos alunos, se reduz o ensino à projeção ou ao adestramento humano.

\section{5) CRENÇAS E MOTIVAÇÃo}

Fernández (2010) define que o ser humano, ao nascer, traz consigo impulsos inatos que geram resultados potenciais e influenciam nas crenças e nos valores pessoais e sociais. Pode-se afirmar que o contexto social gera uma constante influência no indivíduo, refletindo em suas escolhas.

Uma questão fundamental a ser considerada é o fato do processo de ensino e aprendizagem ser composto por alunos e professores, agentes ativos que têm suas atitudes influenciadas por seus pensamentos e percepções. A partir daí, o sujeito toma suas decisões no sentido de manter as suas necessidades, e o sentimento de objetivo alcançado propicia um aumento de autoestima e de autoconfiança que o estimula para ir em busca de um outro desejo.

As crenças e as modificações podem criar no ser humano expectativas positivas ou negativas com relação ao objetivo proposto:

É importante destacar aqui o fato de que o estudo das crenças é imprescindível, pois servirá para o entendimento da forma como as pessoas pensam e do porquê aceitamos algumas coisas como verdadeiras em vez de pensar que essas coisas podem ser questionadas no futuro. As crenças envolvem comprometimentos intelectual e prático, portanto é preciso descobrir as bases sobre as quais elas se apoiam (Alvarez, 2007, p.196).

A motivação do aluno está diretamente relacionada com a do professor pelo seu trabalho, ou seja, um professor motivado, que se dedica a sua classe, possui energia suficiente para estimular uma turma, de acordo com Fernández (2010). A motivação do professor tem um caráter intrínseco, no sentido de que o docente já nasce com um desejo de ensinar e de compartilhar conhecimentos.

\section{6) ATIVIDADES DESENVOLVIDAS EM AULA}

O Centro de Ensino e Pesquisa de Línguas Estrangeiras Instrumentais (Cepesli) da Universidade Federal de Santa Maria oferece para a comunidade universitária e regional um Curso de Espanhol para Viagens que visa a comunicação em países de língua espanhola. São oferecidos cursos de instrumentalização em LE, no sentido de preparar os alunos para uma interação com falantes naturais de ELE. Para isso, são elaboradas atividades que proporcionam aos estudantes a possibilidade de interagir em situações similares às que podem ocorrer em uma viagem. 
Para Alvarez (2007, p. 223), "a sala de aula tida sempre como um ambiente de ensino, hoje se transformou num contexto de pesquisa, rico em dados que podem nos levar a descobrir nossas próprias falhas, a refletir sobre nossas crenças, ações e atitudes para melhorar a qualidade de ensino". A partir dessas colocações, pensou-se em refletir acerca de como a preparação de atividades de qualidade, bem elaboradas e que seguem um objetivo podem favorecer ao processo de ensino e aprendizagem dos alunos.

Parte-se do pressuposto de que a qualidade de ensino deve constituir-se em uma prioridade do processo de ensino e aprendizagem. Os cursos acima citados são normalmente procurados por alunos adultos que apreciam viajar, que viajam a negócios ou que são intercambistas. Nesse caso, para Collins (2004), os adultos são mais curiosos, motivados e entusiasmados intelectualmente para aprender, pois possuem responsabilidade e envolvimento para que a aprendizagem se efetive.

De acordo com Richards (2002), os alunos possuem crenças relacionadas com a aprendizagem. Entre elas está o fato do professor ser o possuidor do conhecimento, o que demonstra a necessidade de trabalhar a autoestima e a segurança do estudante para conseguir desenvolver-se e render em aula.

Na sequência, é apresentada uma série de exercícios que buscam a interação dos alunos e o envolvimento com o tema da tarefa que é uma situação que pode ocorrer em uma viagem. Compreende-se que é importante mostrar aos estudantes que existe uma grande vantagem em aprender a língua-alvo, pois isso pode funcionar como um fator motivacional, de acordo com Fernández (2010). Por exemplo, demonstrar o quanto pode ser facilitado, em um país de língua espanhola, a compreensão da língua e isso exerceria um papel essencial, um diferencial, um agente facilitador na permanência no país estrangeiro.

Quadro 1: Material didático aplicado em aula.

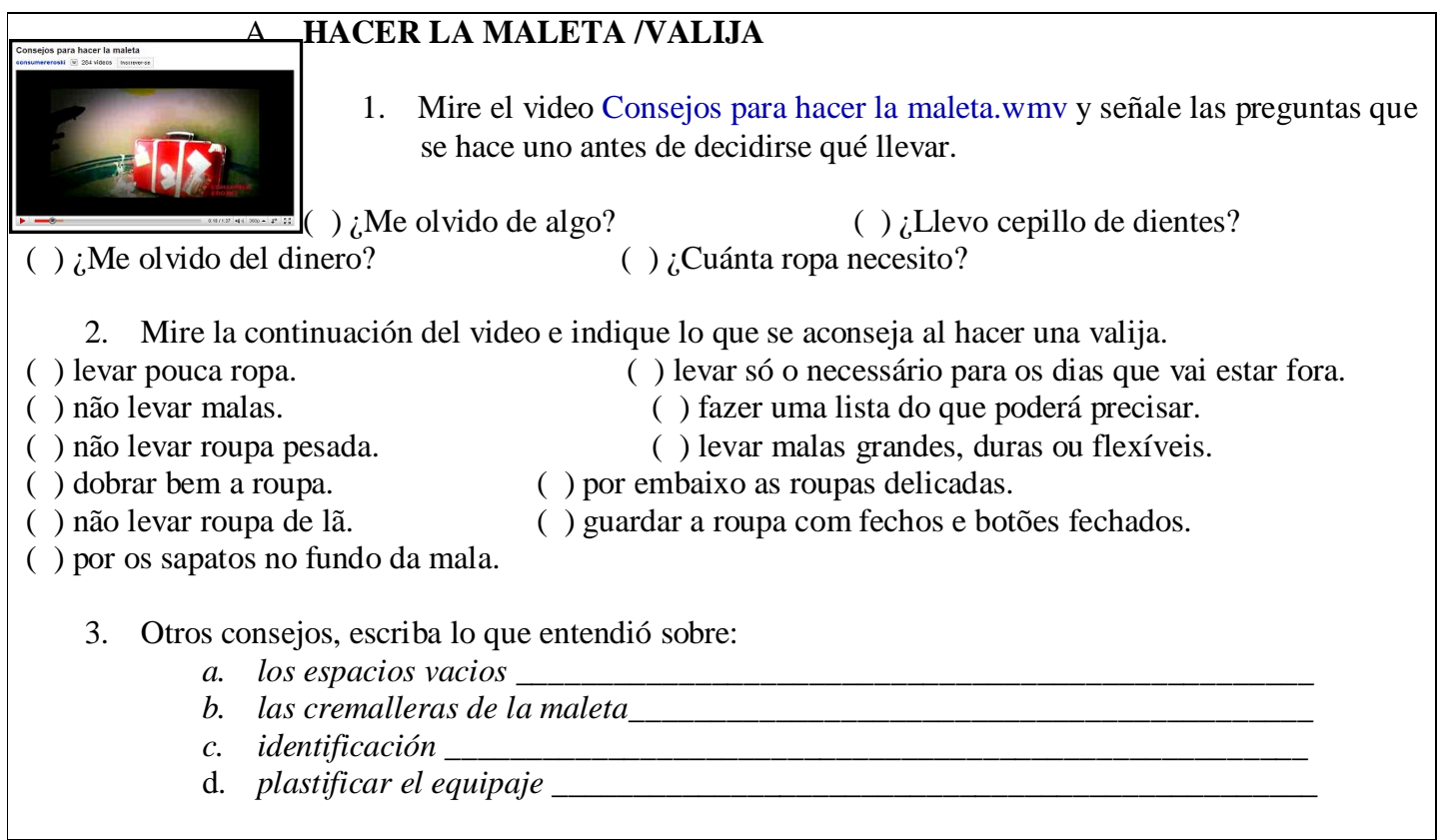

Fonte: Material didático de em curso de Espanhol Instrumental. 
É importante destacar que o fato dos alunos estarem procurando um curso para um fim específico, nesse caso, que os prepare para a viagem, isso serve como um fator motivacional, pois todos estão em busca de um mesmo propósito e se dedicam para ter êxito na procura de seu objetivo. Assim, pode-se dizer que os cursos instrumentais, normalmente, contam com a participação de alunos com um interesse comum e, pela necessidade pessoal estão extremamente envolvidos com a temática do curso.

A utilização de filmes, vídeos, músicas, diálogos gravados, leituras de jornais, revistas, entre outros, é uma excelente alternativa para tornar as aulas agradáveis, diversificadas e criativas. Observou-se, com isso, que a utilização de materiais autênticos ou de situações reais, como a preparação a bagagem e a possibilidade de ouvir falantes nativos estimula a compreensão e fornece um contato legítimo com a língua estrangeira.

$\mathrm{Na}$ tarefa apresentada acima, os estudantes têm acesso a um vídeo com falantes espanhóis, que explicam a melhor maneira de organizar uma mala. Os alunos, além de terem contato com as sugestões apresentadas que vão de encontro às suas necessidades, também têm acesso à língua espanhola falada por nativos. Ao mesmo tempo, tomam consciência de como está o seu nível de compreensão e ainda conhecem mais uma variante linguística e cultural, um vocabulário típico e uma pronúncia característica da região onde foi elaborado o vídeo.

Quadro 2: Material didático aplicado em aula.

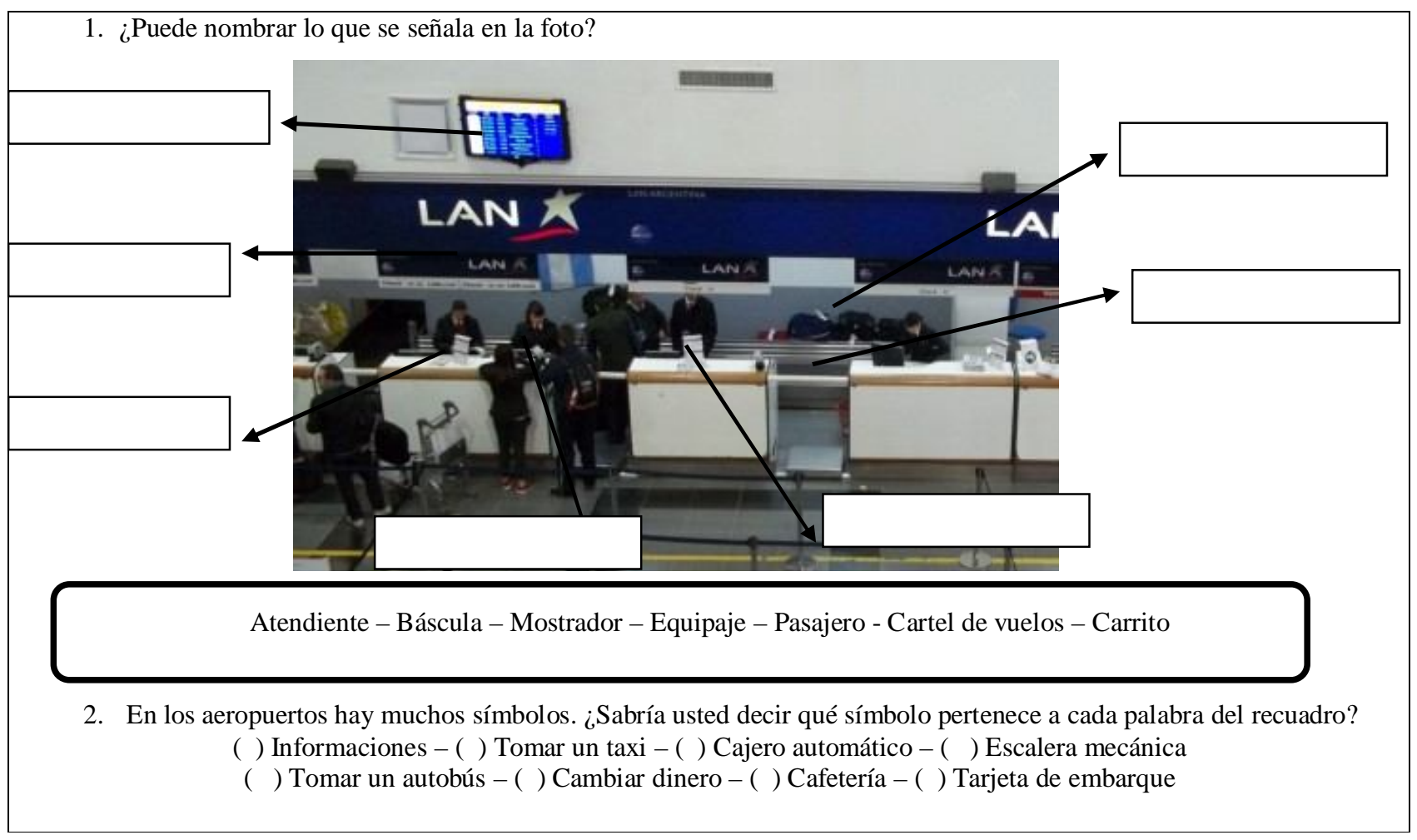




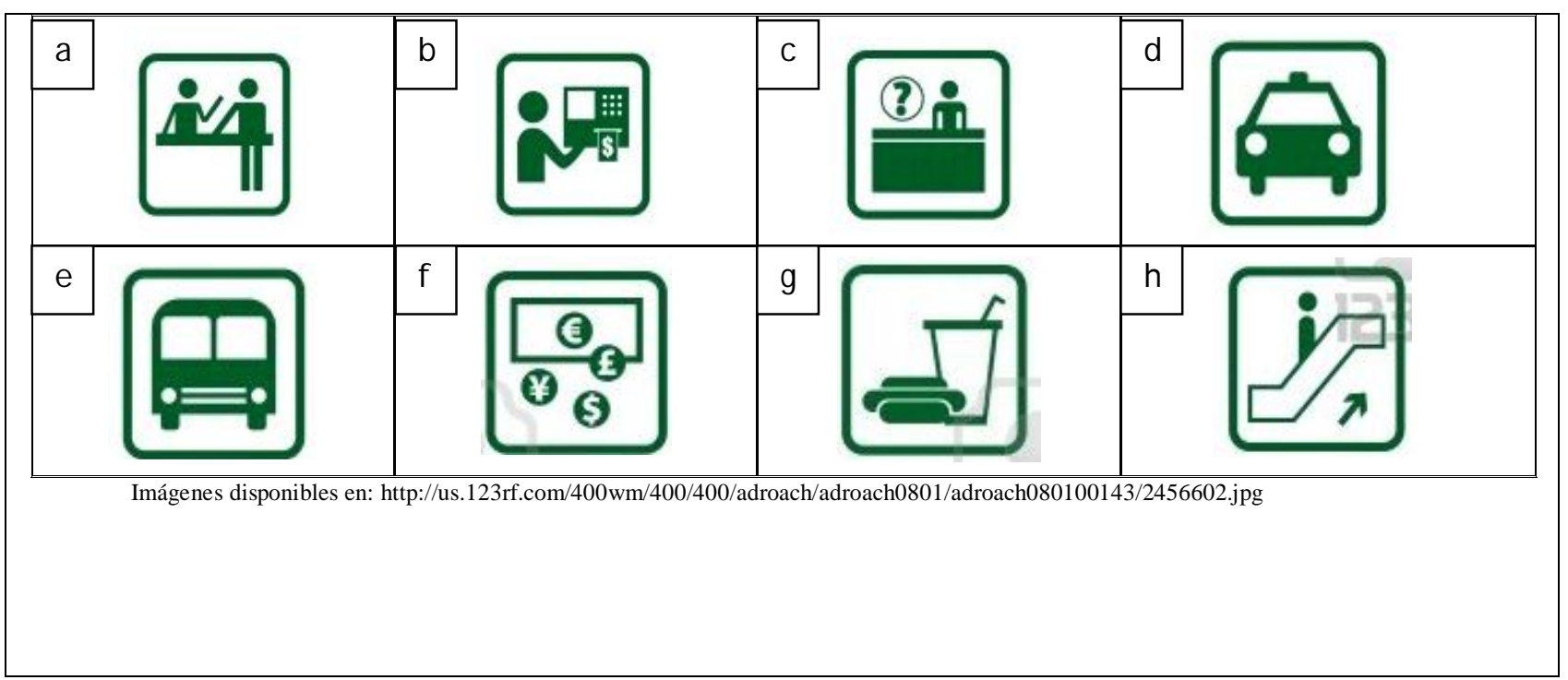

Fonte: Material didático de em curso de Espanhol Instrumental.

Seguindo o raciocínio de Boruchovitch (2010), o professor deve recorrer a uma variedade ampla de materiais didáticos para atender a motivação dos alunos. Desse modo, nessa atividade, os futuros viajantes podem ter acesso a algumas palavras comuns do vocabulário do aeroporto e a situações que podem ocorrer em sua viagem. Mais uma vez, é possível conhecer um conteúdo fundamental em língua estrangeira para quem deseja viajar.

Esse tipo de tarefa estimula a interação, pois percebe-se que os alunos procuram discutir entre eles em aula a resolução da atividade, bem como, muitas vezes, buscam contar suas próprias experiências pessoais. De acordo com Williams (1999), a aprendizagem de idiomas tem um caráter social, porque aprender uma língua estrangeira envolve um interatuar com o outro e em diversas situações desconstruir velhas significações e crenças que se possui.

Outra característica típica dos cursos instrumentais é que, na maioria das vezes, os estudantes esforçam-se para que a comunicação seja sempre em LE. Para isso, é necessário que seja estabelecida uma relação interativa de qualidade e de reciprocidade para que os alunos se sintam à vontade. As crenças dos alunos também podem estar presas ao estilo de aprendizagem que eles seguem. Por isso, é fundamental que interajam com outras pessoas e que possam ter a oportunidade de aprender em grupo.

Avaliar as crenças dos estudantes relacionadas com a aprendizagem é uma tarefa extremamente complexa, para Madeira (2008). Segundo Richards (2002), entre as crenças existentes está o fato do professor ser o possuidor do conhecimento, o que demonstra a necessidade de trabalhar a autoestima e a segurança do estudante para conseguir desenvolver-se e render em aula.

Uma maneira de romper com a timidez é solicitar que os alunos façam a atividade em grupo e a apresentem depois de concluída para a turma, pois os estudantes que aproveitam mais as aulas são os estudantes motivados e ativos. Para motivá-los, o professor, de acordo com Fernández (2010), não deve utilizar somente técnicas pontuais 
que gerarão uma motivação somente momentânea, mas as que possibilitem a construção de um conhecimento que possa ser útil para diversas circunstâncias da vida do discente. Evidencia-se que para formar um ambiente motivador, é fundamental que a participação, o engajamento e o prazer em aprender sejam estimulados e compreendidos como fundamentais para o andamento da aula.

Quadro 3: Material didático aplicado em aula.

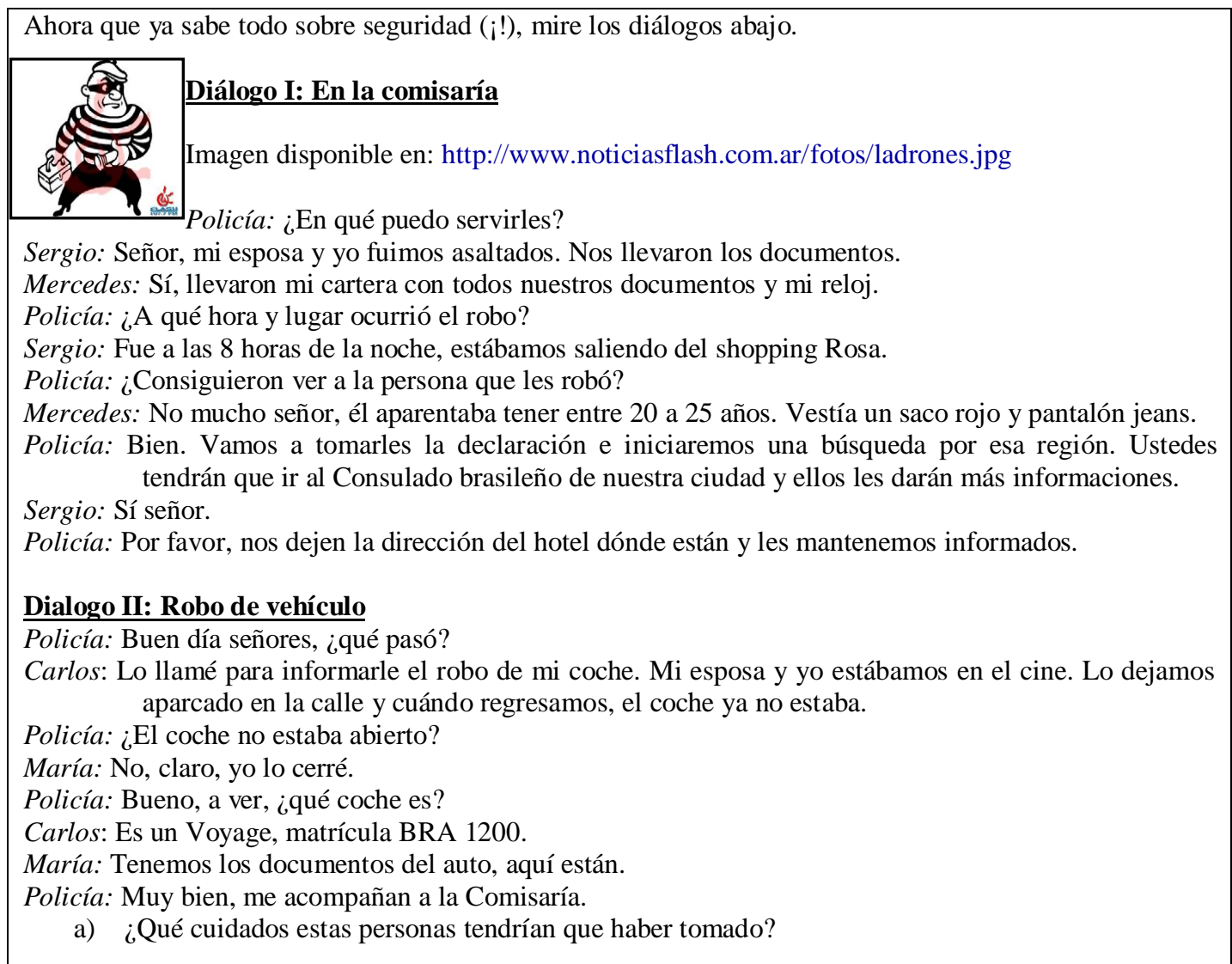

b) ¿Alguna vez le ha sucedido un robo o algo parecido? ¿Qué pasó? ¿Cuándo sucedió? Cuente esa experiencia a sus colegas.

desenlace para la situación en que se encuentran los personajes.

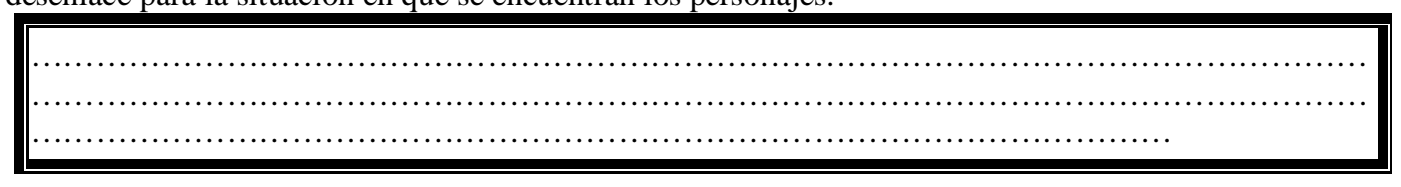

Fonte: Material didático de em curso de Espanhol Instrumental. 
Esse exercício é um pouco mais complexo, porque procura contextualizar o estudante na história do diálogo, sendo necessário, com isso, que recorra a seus conhecimentos pessoais sobre o tema que está sendo trabalhado. É imprescindível a realização da escolha de um dos dois diálogos e que seja elaborado um final para ele.

Destarte, além do aluno compreender a língua, deve também ser criativo para elaborar uma conclusão interessante para a narrativa. Assim sendo, todos esses aspectos apresentados acima fortalecem a importância da utilização de atividades didáticas motivacionais e que proporcionem o aprendizado.

\section{7) CONSIDERAÇÕES FINAIS}

Esse trabalho procurou apresentar alguns pressupostos teóricos acerca das crenças e da motivação que fazem parte do processo de ensino e aprendizagem de línguas estrangeiras instrumentais e também promover uma discussão sobre algumas atividades referentes ao estabelecimento da motivação e do entendimento das crenças presentes nesse processo.

A motivação pode ser considerada como importante para que o sujeito mantenha o desejo de ir em busca de um objetivo o que, ao mesmo tempo, propicia um aumento de autoestima e de autoconfiança para continuar procurando pelo que quer. Do mesmo modo, como foi discutido no decorrer do artigo, a presença das crenças no processo de ensino e aprendizagem de LE é algo que exerce uma forte influência não só no trabalho do professor como no estudo do aluno.

Foi possível perceber, ao final do presente estudo, baseado em observações realizadas na sala de aula e em leituras efetuadas para a compreensão da importância do tema, as marcas deixadas pelas crenças e pela motivação são fatores relevantes para serem pesquisados e considerados.

A partir dessas colocações, referentes ao estudo instrumental de línguas, pode-se dizer que é essencial que os professores tenham conhecimento da real importância do desenvolvimento de um ambiente escolar favorável para o estabelecimento de relações interativas, melhor dizendo, para a formação de um espaço, no qual seja possível por parte dos discentes e dos docentes a interação, a participação e a discussão colaborativa. E, com isso, compreender e desmistificar o surgimento de crenças e, ao mesmo tempo, motivar os alunos a manterem-se estimulados para o estudo. Assim, acredita-se que poderá ser construído um processo de ensino e aprendizagem mais saudável, agradável e produtivo.

\footnotetext{
i Redes de Conversação, consoante Maturana (2004) são todos os contatos estabelecidos entre os seres humanos por meio da linguagem e pelos quais são transmitidos sentimentos, fatos, saberes.

ii Língua Estrangeira.
}

\section{REFERÊNCIAS BIBLIOGRÁFICAS}


ALVAREZ, M. L. O. ; SILVA, K. A. . Crenças, motivações e expectativas de alunos de um curso de formação Letras/Espanhol. In: Maria Luisa Ortíz Alvarez; Kleber Aparecido da Silva. (Org.). Lingüística Aplicada: Múltiplos olhares. 1 ed. Campinas: Pontes, 2007, v. 1, p. 191-231.

ANTUNES, Celso. Alfabetização Emocional: Novas Estratégias. 10ª ed. Petrópolis: Editora Vozes, 2003.

BARCELOS, Ana Maria F. Metodologia de pesquisa das Crenças sobre Aprendizagem de Línguas da Arte. In: Revista Brasileira de Lingüística Aplicada, vol. 1, no. 1. Belo Horizonte: Faculdade de Letras da UFMG, 2001. p. 71-93.

Crenças sobre aprendizagem de línguas, Lingüística Aplicada e ensino de línguas. In: Linguagem \& Ensino, vol 7, nº 1, 2004. p. 123 -156.

BORUCHOVITCH, Evely; BZUNECK, José Aloyseo (orgs). A Motivação do aluno: Contribuições da Psicologia Contemporânea. $4^{\mathrm{a}}$ ed. Petrópolis, RJ: Editora Vozes, 2009.

BORUCHOVITCH, Evely; Bzuneck, José Aloyseo; GUIMARÃES, Sueli Édi Rufini (orgs). Motivação para Aprender: Aplicações no Contexto Educativo. Petrópolis, RJ: Editora Vozes, 2010.

BZUNECK, J. A. A Motivação do aluno: Aspectos Introdutórios. In: BORUCHOVITCH, Evely; BZUNECK, José Aloyseo (orgs). A Motivação do aluno: Contribuições da Psicologia Contemporânea. Petrópolis, RJ: Editora Vozes, 2004, p. 9-36.

CHALITA, Gabriel. Educação: A Solução Está no Afeto. 9a ed. São Paulo: Editora Gente, 2001.

CHARLOT, Bernard. Pedagogia da autonomia: saberes necessários à prática educativa. São Paulo: Paz e Terra, 2004.

CLAXTON, Guy. O Desafio de Aprender ao Longo da Vida. Porto Alegre: Artmed, 2005.

COLLINS, Jannette. Education Techniques for Lifelong Learning. In: Lifelong Learning. University of Wisconsin and Clinics: Radiographics, 2004.

FERNÁNDEZ, Gretel Eres; CALLEGARI, Marília Vasques. Estratégias Motivacionais para Aulas de Língua Estrangeira. São Paulo: Companhia Editora Nacional, 2010.

FREIRE, Paulo. Pedagogia da Autonomia: Saberes Necessários à Prática Educativa. 29a ed. São Paulo: Editora Paz e Terra, 2004. 
FREITAS, Luciana Maria Almeida de. Espanhol Instrumental. In: Actas del Congreso Brasileño de Profesores de Español. Brasilia: Thesaurus Editora de Brasília, 2005, p. $49-56$.

GRACÍA, Marta Higueras. Como elaborar material para internet, para La enseñanza de español con fines específicos. In: I Congreso Internacional de Español para Fines Específicos. España: Centro Virtual Cervantes, 2000, p. 75-85. Disponível em: http://cvc.cervantes.es/ensenanza/biblioteca_ele/ciefe/pdf/01/cvc_ciefe_01_0010.pdf.

Acesso em: 15 de novembro de 2011.

KNÜPPE, Luciane. Motivação e Desmotivação: Desafio para as Professoras do Ensino Fundamental. In: Educar. Curitiba: Editora UFPR, 2006, n. 27, p. 227-290.

MADEIRA, Fabio. Alguns Comentários sobre o Papel das crenças de alunos e professores no Processo de Aprendizagem de um Novo Idioma. In: Letras \& Letras. Editora da Universidade Federal de Uberlândia EDUFU: Uberlândia, 2008, vol.24, p. 49-57.

MARTINS, Emili Barcello; ROCHEBOIS, Christianne Bennati; Paula, Maria Eugênia da Matta Machado de. A abordagem instrumental no ensino de língua francesa na universidade federal de viscosa, MG. Universidade Federal de Viçosa, MG. Disponível

em: www.fbpf.org.br/cd2/liste_des_auters/m/emili_barcellos_martins_christianne_bennati_r ochebois_maria_eugenia_matta_machado_paula.pdf. Acesso dia: 02/09/09.

MATURANA, H.; VERDEN-ZÖLLER, G. Amar e brincar: fundamentos esquecidos do humano. São Paulo: Editora Palas Athena, 2004.

NARDI, Nádia. Como surgiu o Projeto de Inglês Instrumental no Brasil. In: Revista Voz das Letras, $n^{\circ} 3$. Concórdia, Santa Catarina: Universidade do Contestado, 2005.

RAMOS, Rosinda C. G. Instrumental no Brasil: a desconstrução de mitos e a construção do futuro. In: FREIRE, M.; ABRAHÃO, M. H. V.; BARCELOS, A. M. F. (Orgs). Linguiística Aplicada e Contemporaneidade. Campinas, SP: Pontes, 2005. p.109-123.

RICHARDS, Jack C.; LOCKHART, Charles. Estrategias de Reflexión sobre la enseñanza de Idiomas. Madrid, España: Cambridge University Press, 2002.

SALTINI, Cláudio J. Afetividade e Inteligência: a emoção na educação. 4 ed. Rio de Janeiro: DP\&A editora, 2002.

SEDYCIAS, João. O que é inglês instrumental? Universidade Federal de Pernambuco. 2002. Disponível em: http://www.sedycias.com/instrument_01e.htm. Acesso dia 02/09/09.

SILVA, Kleber Aparecido da. Crenças no Ensino-Aprendizagem e na Formação de Professores de Línguas: Delimitando e Atravessando Fronteiras na Linguística Aplicada 
Brasileira. In: Crenças, discursos \& linguagem. Vol.1. Campinas, SP: Pontes Editores, 2010.

SILVA, Kleber Aparecido da. Crenças no Ensino-Aprendizagem e na Formação de Professores de Línguas: Delimitando e Atravessando Fronteiras na Linguística Aplicada Brasileira.In: Crenças, discursos \& linguagem. Vol.1. Campinas, São Paulo: Pontes Editores, 2010.

Crenças no Ensino-Aprendizagem e na Formação de Professores de Línguas: Pontos e Contrapontos. In: SILVA, K. A. (org.) Crenças, Discursos \& Linguagem, volume II. Campinas, São Paulo: Pontes Editores, 2011.

VASCONCELOS, Maria Lucia M. Carvalho; Brito, Regina Helena Pires de. Conceitos de Educação em Paulo Freire. $3^{a}$ ed. São Paulo: Editora Vozes, 2009.

VIANA, Wyllds Carraro; CARAZZAI, Marcia Regina Pawlas. Crenças de Professores e Alunos a Respeito de Ensino e Aprendizagem de um Língua Estrangeira. Revista Eletrônica Interfaces, vol. 01, n.01. Guarapuava, PR: UNICENTRO-Universidade Estadual do Centro-Oeste, 2010. Disponível em: http://revistas.unicentro.br/index.php/revista_interfaces/article/view/894/962. Acesso em: 15 de Outubro de 2011.

WILliAMS, Marion; BURDEN, Robert L. Psicología para Profesores de Idiomas: Enfoque del Constructivismo. Madrid, España: Cambridge University Press, 1999. 